Int. J. Electrochem. Sci., 11 (2016) 3786 - 3802

International Journal of

ELECTROCHEMICAL

SCIENCE

www.electrochemsci.org

\title{
Effect of Zeta Potential of Exfoliated Amphiphilic Montmorillonite Nanogels on Removal Efficiencies of Cationic Dye water pollutant
}

\author{
Ayman M. Atta ${ }^{1,2, *}$, Hamad A. Al-Lohedan ${ }^{1}$, Z. A. ALOthman ${ }^{3}$, Ahmed M. Tawfeek ${ }^{4}$, Ayman \\ AbdelGhafar ${ }^{3}$ Nora A. Hamad ${ }^{5}$ \\ ${ }^{1}$ Chemistry Department, College of Science, King Saud University, Riyadh, Kingdom of Saudi \\ Arabia \\ ${ }^{2}$ Egyptian Petroleum Research Institute, Nasr City, Cairo 11727, Egypt \\ ${ }^{3}$ Chemistry Department, College of Science, King Saud University, Riyadh, Kingdom of Saudi \\ Arabia \\ ${ }^{4}$ College of Science, King Saud University, Riyadh, Kingdom of Saudi Arabia \\ ${ }^{5}$ Department of Chemistry, Faculty of Science \& Arts, Al Jouf University, Qurayyat, Saudi Arabia \\ *E-mail: aatta@ksu.edu.sa
}

doi: $10.20964 / 110379$

Received: 17 January 2016 / Accepted: 19 March 2016 / Published: 1 April 2016

\begin{abstract}
The zeta or electrokinetic potential describes the nanomaterials potential distribution and it is often a useful parameter to evaluate the adsorption of ionic pollutants on the nanomaterials surfaces, since it reflects the electrostatic interactions of water pollutants on the nanomaterials surfaces. In this respect, sodium montmorillonite (Na-MM) attracted great attention in the removal of toxic pollutants from water. The present work aims to increase the ability of MMT to act as amphiphiles to increase the diffusion of pollutants into MMT galleries. The exchange of Na cations with a cationic monomer based on 3-acrylamidopropyl trimethylammonium chloride followed by crosslinking copolymerization achieves this goal. Therefore, different MMT copolymer nanogels based on APTAC were prepared using anionic and nonionic co- monomers and characterized by FTIR, TEM, WXD, and zeta potential analyses. The surface activity of the amphiphilic MMT nanogels was evaluated from the surface tension measurements. The adsorption of MB on the surface of Na-MMT was studied at different MMT nanogel concentrations, and $\mathrm{pH}$ through zeta potential measurements. The removal efficiencies of MMT nanogels for removing methylene blue as cationic dye from water were measured at room temperature and $\mathrm{pH}$ 7. The data indicated that the removal efficiencies of MMT nanogels increased by complete exfoliation of MMT layers and their high surface activity that increased the MB penetration into the network of MMT nanogel.
\end{abstract}

Keywords: Zeta potential; water pollutants; sodium montmorillonite; adsorption; cationic dye. 


\section{$\underline{\text { FULL TEXT }}$}

(C) 2016 The Authors. Published by ESG (www.electrochemsci.org). This article is an open access article distributed under the terms and conditions of the Creative Commons Attribution license (http://creativecommons.org/licenses/by/4.0/). 